\title{
The Global Diffusion of Work-Injury Insurance: The Role of Spatial Networks and Nation Building
}

Nate Breznau, (D) 0000-0003-4983-3137, breznau.nate@ gmail.com

Felix Lanver, (iD 0000-0002-0352-7508

University of Bremen, SOCIUM Research Center on Inequality and Social Policy

Forthcoming chapter:

Breznau, Nate and Felix Lanver. 2021. “The Global Diffusion of Work-Injury Insurance: The Role of Spatial Networks and Nation Building." In Windzio, Michael, Helen Seitzer, Fabian Besche and Ivo Mossig. Networks and Geographies of Global Social Policy Diffusion. Palgrave.

\begin{abstract}
Work-injury law often marks the beginning of the modern welfare state. We argue that work-injury insurance is particularly important to nation state building: it placates myriad social groups' while binding them symbiotically with the state. We analyse any first laws and first social insurance as outcomes in 150 states (1880-2010). Our network diffusion and event history models reveal that spatial proximity and democratization are key predictors of first laws. However, nation state formation and trade density are additional predictors of social insurance. We conclude with these findings' implications for understanding nation building within global networks.
\end{abstract}




\section{Introduction}

Work-injury laws, also historically known as workmen's compensation and accident insurance, are among the oldest welfare state laws. Often marked by scholars as the beginning of the welfare state (Abbott and DeViney 1992; Flora and Alber 2009). They extended basic principles of responsibility for damages done to persons or property found in civil and common law traditions. Their implementation coincides with new dangerous forms of employment in factories, mechanized extraction and construction that come with industrialization. The workers, families and communities affected by these new industrial risks demanded protection, putting pressure on policymakers (Wilensky 1975; Kangas 2010).

Usually the first work-injury law introduced in a state was employer liability. Although these laws often standardized compensation levels and explicitly covered work-related damages, they did little to reduce worker subversions and revolts. They mostly did not insure against risk because the burden of proof of harm fell on the worker and compensations were small and limited in duration (Flora and Alber 2009). More advanced and effective laws involved the creation of social insurance. These placed all employees into an insurance scheme, with automatic entitlements to compensation unless otherwise proven by the employer or insurance agency in court. Social insurance offered financial predictability, a peaceful workplace and protection of both employers and employees from legal battles (Tripp 1976; Berkowitz and Berkowitz 1984; Pavalko 1989).

Employer liability laws tended to pave the way for social insurance laws. However, history suggests no standardized trajectory (Haggard and Kaufman 2008). Laws have only a weak correlation with industrialization and democratization, leaving functional theories limited in capacity to explain crosscountry patterns of welfare state development (Alber 1982). For example, Britain was the earliest industrializing society and quite democratic, but a latecomer to social insurance in 1934. Germany was less industrialized and less democratic, but a pioneer in 1884. Meanwhile, France was similarly developed as Germany and slightly more democratic, but only introduced social insurance 10 years later in 1894 (Breznau and Lanver 2020).

Factors of political economy are likely responsible for such variation. Work-injury social insurance along with other forms such as pensions and health care, are an important strategy in nation building. They shift the burden of individual risk to the collective level, meaning that workers and society become bound together with a common welfare interest. This is an adaptation of military conscription strategies. Dating back to the Greeks and Romans, ruling powers used the promise of veteran benefits to motivate and 
compensate soldiers engaged in potentially deadly work to defend the territory and its people (Ierley 1984). Soldier provisions often included forms of health care, pensions, survivor benefits and compensation for injuries obtained on duty. The utility of welfare provisions for expanding and defending a nation's borders, simultaneously aided in developing and expanding allegiance of soldiers to that nation (Obinger et al. 2018).

\section{Theoretical Framework: Nation State Institution and Codification}

The idea of a nation state and democratic rule of law was quite new in the late 1800 s when states first started making national work-injury policies. It was precisely the expansion of rights by a state that led to workers having new forms of power (voting, the right to organize) to exert in the state. At the same time, the architects and policymakers developing nation states were able to build allegiance to the state among workers by offering rights to workers (Marshall 1950), and with these right came institutional developments that strengthened the worker-state relationship (i.e. collective bargaining and work injury schemes). The allegiance of these populations was crucial to nation building because they represented the largest segments of society demographically and were increasingly exposed to worker resistance tactics through urban concentration and the spread of Communist doctrine.

Theories of power resources and institutions argue that politics and the ability of special interests to organize and exert power influenced the timing and scope of work-injury laws. As argued by Korpi (1983), the agents of the working class, especially unions, socialist movements and 'left'-parties competed with employer organizations and special interest groups for influence in the organization of the economy and building of state-regulated institutions. The mobilization of the working class, motivated in particular by the spread of new socialist ideas, imposed pressure on the old and new power elites, forcing them to take strategic action. It is thus a combination of power resources and ruling strategies which fostered the stabilizing role of social insurance in nation state building. The Communist movements were just one example of the threat of revolution that lurked among populations in early European state building after the French Revolution (Breznau 2020).

In Bismarckian Germany for example, the introduction of social insurance went hand-in-hand with the Sozialistengesetze, various laws prohibiting a range of socialist, social-democratic and communist associations. These laws were dismantled in 1890 due to the continued success of the socialist party and its allies; however, by this point Germany had introduced the world's first national, and relatively comprehensive work-injury social insurance scheme. Arguably, this contributed to the failure of a 
socialist revolution despite strong socialist organization. Béland and Koreh (2019) review nation state building in both Canada and Israel and find a prominent role of social insurance policies in state building, despite extremely different historical and institutional trajectories. Just as with taxes, the authors stress the importance of revenue raising in contributory schemes, emphasizing the possibility to use those programs to expand states fiscal capacities and legitimacy. Essentially, as the state legislates in more areas and controls or regulates more forms of insurance, it becomes indispensable to the economy and social welfare. Whether giving or regulating or simply reacting to worker revolts, state building was certainly not a linear, 'friendly' process, but one of contradictions and conflict. Nation building entails attempts to vest the highest level of power and authority into nation state governance, a power to which all other power resource groups (parties, unions, employer organizations, etc) are subjugated. From a Gramscian perspective, this would be construction of a hegemonic state through both coercion (strong laws against revolutionary organizations) and consent (providing citizenship, new rights and social insurance).

State leaders and policymakers did not operate in isolation. They constantly engaged in policy learning from other states as they competed not only for strengthening local rule, but also for regional and global power and stability. This was facilitated by international organizations, political treaties and trade. Liu and Leisering (2017) argue that the adoption of a Bismarck oriented scheme is the product of international norm setting by the International Labor Organization (ILO). For example, Japan directly imported German civil law and later Bismarckian social insurance principles in its (strong) state development, and the latter was specifically intended to head off labor problems witnessed across Europe (Gordon 1985). The Communist party was certainly an international organization by the late 1800 s and had great influence on worker movements even before the ILO.

It is therefore our main contention that work-injury and especially social insurance were particularly important in the process of nation building. Given that work-injury protection in the form of social insurance tended to preclude or coincide with other forms of social security (pensions and unemployment protection for example), it should be a key event in the construction of successful nations. As it requires legitimacy and a clear nation state within which to enact the policy, it should come in the early stages of nation state development. Therefore, we hypothesize that social insurance is more likely in the years immediately after nation state formation.

At the same time, employer liability policies were often enacted to placate, rather than empower workers. They paid lip service to worker movements and calls from elites or humanistic organizations to help the lot of the suffering workers. In many cases they were simply laws to achieve recognition and clout with 
internationally as with the powerful ILO whose early conventions included workmen's compensation (C012 1921 \& C017 1925). Given that employer liability laws did not specifically link workers with the state in a solidaristic way because they left the burden of proof (thus risk) on the workers, we expect that enactment of employer liability laws is not more likely in the years immediately after nation state formation.

We incorporate our unique hypotheses within the larger theoretical perspective motivating the collective research in this book. Namely, we are also investigating the development of social policy as a process of global diffusion, so we test our hypotheses while simultaneously attempting to account for diffusion and historical trajectories. Diffusion processes related to colonialism, trade, migration and culture are often theorized and tested in the development of social spending or the introduction of welfare state laws (Collier and Messick 1975; Schmitt 2015; Egger et al. 2017); but we are aware of no study that simultaneously accounts for both density of adoption among network ties, and event history trajectories to estimate the likelihood of adopting work-injury insurance.

\section{Data and Methods}

All data and replication materials are available in our Project Repository ${ }^{1}$.

We use the Global Work-Injury Policy Dataset (GWIP v1.0) (Breznau and Lanver 2020) to measure the year of introduction for our dependent variables first law and first social insurance. We recode the latter to the year when all formal blue-collar workers were covered, as some countries introduced a first social insurance law covering only certain segments of the labor force. To be consistent with our nation building theory, the law should apply to the industrial, blue-collar workforce whose allegiance is arguably necessary for national success. Full information on all covariates are available for 150 countries from 1880-2010.

Our primary test variable is the year that a country became an independent state and the four years following. We also include the year prior to state formation to account for any measurement error associated with chopping time data into yearly cases; in two cases a law appears the year before state formation as coded in the data but are clearly part of the state formation process which also starts often many months or years prior to declaration of independence. To identify state formation, we take the

\footnotetext{
${ }^{1} \underline{\text { https://github.com/nbreznau/work_inj_diff }}$
} 
institution of a state government that had autonomous or semi-autonomous (usually under the purview of a monarch) domain over policymaking most often established via a constitution and covering consistent borders or people as our criteria. For example, Germany in 1871 and Japan in 1890.

Our other independent variables in the analysis account for modernization and political regime by measuring GDP per capita in 10 thousand 2010\$US and the degree of democratization using the regime scale from the Varieties of Democracy project. The latter is a continuous measure from most authoritarian to most democratic. Next we incorporate three network variables measuring culture, trade and spatial proximity. These variables are described in detail in Chapter 1. Briefly, culture refers to similarities on time-varying indicators of political liberties, rule of law, gender roles, dominant religion, language group, government ideology, and Huntington's classification of civilizations. Trade refers to dyadic trade densities provided from the Correlates of War data and spatial proximity refers to capital distances. As network variables they measure both dyadic network linkages and the rate of diffusion among closer (or at all) ties. Thus, their effects are weighted, a process also described in more detail in Chapter 1.

We tested two network diffusion effects of colonialism, one normalized where the effect of colonialism is constant after colonialism ends and one where former colonies are still treated as part of the colonial network after independence; however, in both cases the point estimates are either close to zero or show huge confidence intervals so we leave both versions of this variable out of our main results (see Project Repository for more details). Consistent with modernization arguments we tested robustness of our findings using percent of the labor force in agriculture for a restricted 83 country sample using the Banks CNTS data, but it was not any more informative than our GDP variable.

\section{Results}

We start with a descriptive portrayal of the event of nation state formation in Figure 1. Each row of the figure on the $y$-axis is a single country plotted across the years 1880-2010. We centered the year measure so that year of state formation is zero. Thus, the black vertical line is when each state became independent. The dark grey segments represent time periods in each nation's history where there was no work-injury coverage. The brown segments indicate a country has employer liability, and the green segments indicate a work-injury social insurance scheme. 
Figure 1. Nation State Formation as a 'Treatment' Effect for the Introduction of Work-Injury Law

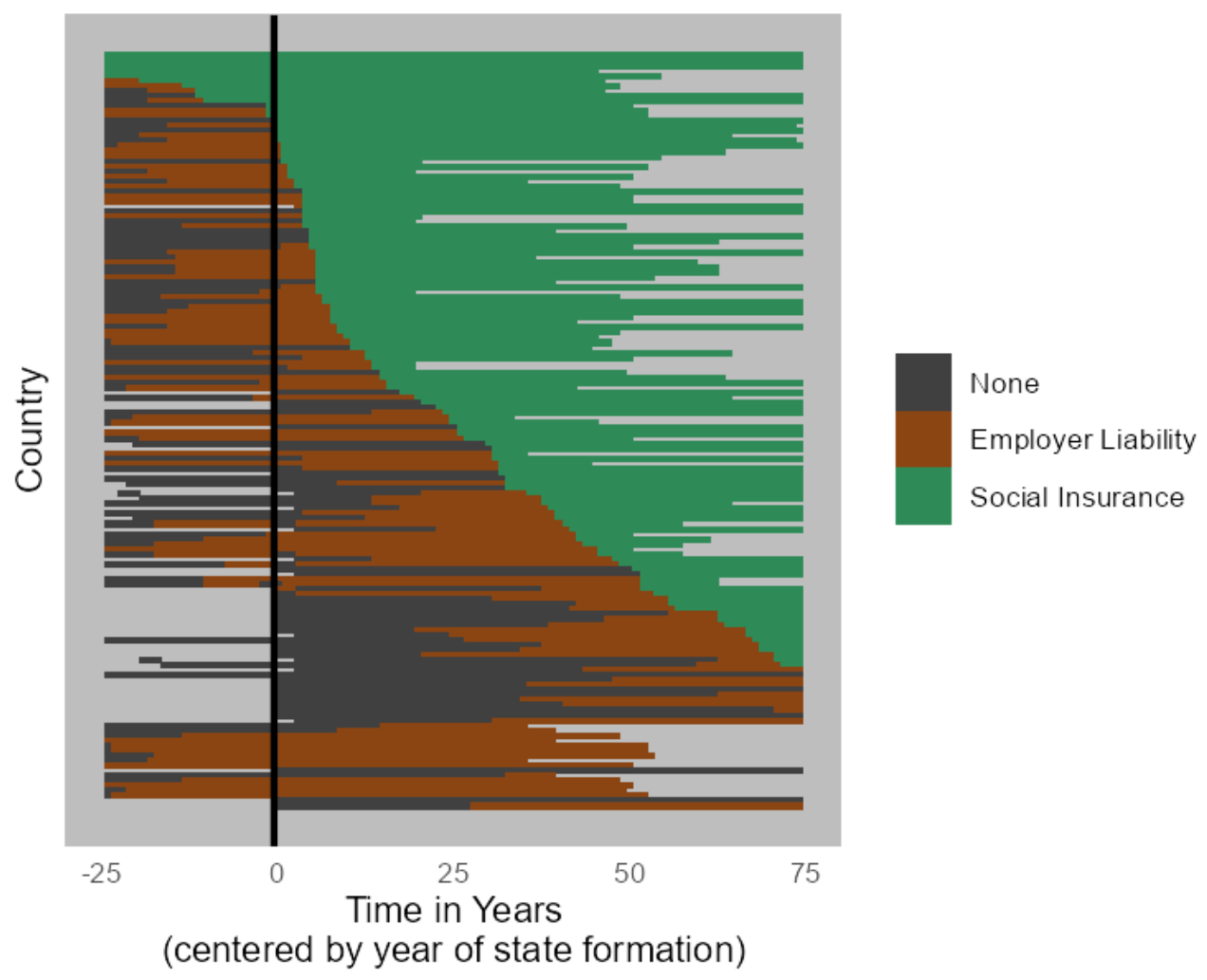

Figure 1 shows that social insurance is something ubiquitously introduced after nation state formation.

This means that establishing a constitution, declaring independence or various other events that established a politically self-ruling state entity is an event that occurs prior to social insurance introduction. A total of 133 out of 150 countries (89\%) introduced social insurance. Of countries that ever introduced social insurance until 2010, 25 (19\%) introduced it during state formation. Moreover, many countries that have not introduced social insurance are much younger countries (indicated by the missing segments in the lower-right of Figure 1). Whether this is a causal relationship, we cannot conclude; however, the fact that many states establish social insurance at the moment of statehood or within the first 4 years thereafter suggests that social insurance is often part of state and nation building given that many other factors are at play, and nation building is a process that is continual rather than discrete. Further evidence comes from our regression models whose main coefficients are displayed in Figure 2 (full models found in Table 1 in the Appendix). 
Figure 2. Discrete Time Hazard Diffusion Models of Work-Injury Law in 152 countries, 1880-2010, Log-Odds

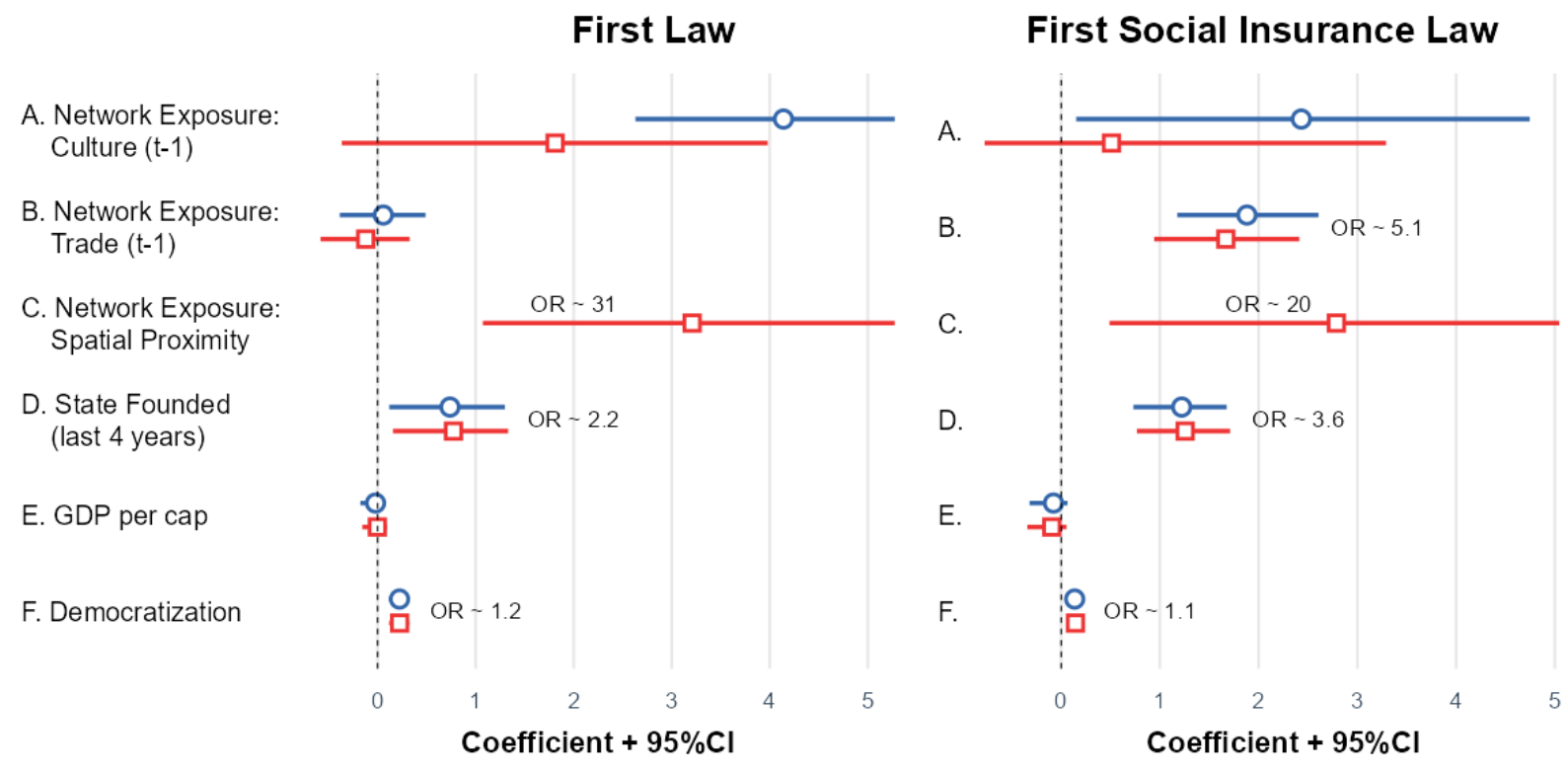

In Figure 2, the blue lines refer to Model 2 and the red lines to Model 3 (see Table 1 below in Appendix), these models are identical except for the inclusion of network exposure by spatial proximity. Moreover, Models 2 and 3 are otherwise identical for the dependent variable first law (left panel, Models "A" in Table 1) and first social insurance (right panel, Models "B"). The results reveal that spatial proximity, state founded and democratization all exhibit positive statistical associations with the yearly likelihood of adopting a first law. The effects are considered important because they reflect a plausible statistical range that is significantly greater than zero with a $95 \%$ confidence interval (CI) after robust clustering standard errors by country. The "OR " labels added to the plot for the significant coefficients are exponentiated coefficients, 'odds-ratios', representing the increase in likelihood of adoption in any given year with a one-point increase in that variable, all else equal.

The spatial proximity variable is weighted by both the distance between the states and the percent of members adopting a first law, thus it is difficult to interpret. However, we can say that the difference between having few other states nearby adopting and most states nearby adopting is a 31-fold increase in the likelihood of adoption in a given year. The CI is very wide, so this is not a highly reliable value and might range from just a few times more likely to 50 times more likely.

The state founded variable suggests a 2.2-fold increase in likelihood of adopting a first law, and the democratization variable has a 1.2-fold increase. However, we have to keep in mind that odds-ratios are 
always relative to the actual baseline likelihood of adoption in a given year. This is difficult to pinpoint because of the time period dummies necessary in this type of model. In Table 1 we see that an average likelihood of adoption in any given period of a first law (Model 3A) is 0.003 or roughly $0.3 \%$. The state founded variable represents a $(2.2 * 0.3 \%=) 0.66 \%$ likelihood of adoption. The window of 5 years of state formation is our test variable, thus the likelihood of adopting at some point in the entire 5-year period is $3.3 \%{ }^{2}$. The democratization variable is measured on a scale from 0 to 9 , so we can say that when a state goes from a score of 2 (or 'rather authoritarian') to a score of 7 ('rather democratic') the odds actually increase by $\left(5^{*} 1.2=\right) 6$-fold leading to a likelihood of $(6 * 0.3 \%=) 1.8 \%$. A perceptibly large increase.

The results are slightly different for adoption of a first social insurance law. Here network exposure to trading partners matters as well as the other significant effects for any first law. Here we can say that state founded variable is even more influential. Taking again a rough average of $0.3 \%$ baseline likelihood (Model 3B) a country is $\left(3.6^{*} 5=\right)$ 18-fold more likely to adopt during state formation, which is an overall odds of $\left(0.3^{*} 18=\right) 5.4 \%$ to adopt in that period. This is a considerable sized likelihood over such a long time span.

Note that our selection of Models 3A and 3B was supported by a better fit to the data than Models 1 or 2 or any robustness checks in both dependent variables' cases.

\section{Discussion}

A political economy perspective on institutions suggests that democratic regimes are more likely to enact universal policies because the citizens are relatively equal, at least in comparison to authoritarian regimes where certain groups are often targeted to maintain power (Grünewald 2021). The measure is fraught with uncertainty however, as who qualified as a voting citizen changed dramatically over time. Women were excluded early in democratic development and often racial/ethnic/religious groups as well. Moreover, workers were not citizens in early democracies and the franchise extended only slowly from high status landowners or nobility to petty bourgeoisie to the working masses.

What is ostensibly striking is the lack of association of GDP with likelihood of adoption. Yet we are careful here, because democracy could be seen as a process of modernization, at least as a form of institutional isomorphism along a modernizing trajectory. Therefore, we do not interpret the GDP

\footnotetext{
${ }^{2}$ Cumulative probability over $X$ years calculated as $1-\left(100-[\text { percent likelihood in year }]^{\wedge} X / 100^{\wedge} X\right)$
} 
coefficient as evidence against the modernization thesis. It is more likely an artifact of event history modeling in many countries. The ranking of countries in 1900 is roughly the same in 2000 in terms of GDP and this means that most countries follow more or less a yearly, linear trajectory in GDP growth. Therefore, GDP tracks time in the hazard model and therefore fails to offer unique variance in the model. To demonstrate that modernization probably matters we divide our countries into a mean split between 'high' and 'low' by GDP in 1900. Then we plot the cumulative hazard rates of adoption in Figure 3 by group. The darker blue hazard lines show that those with higher GDP in 1900 are more likely to adopt sooner than those with lower GDP in 1900. This is evidence of the role of GDP, but we could of course divide the sample into more and less democratized and possibly certain western cultural spheres and not, and plot a similar hazard rate trajectory. As these are all interrelated, we do not argue for a direct effect of GDP per se, but are careful not to rule out development and modernization as playing an important role here, also indicated by a large effect of democratization in our models.

\section{Figure 3. Cumulative Hazard Rates of Adoption by Low versus High GDP in 1900}

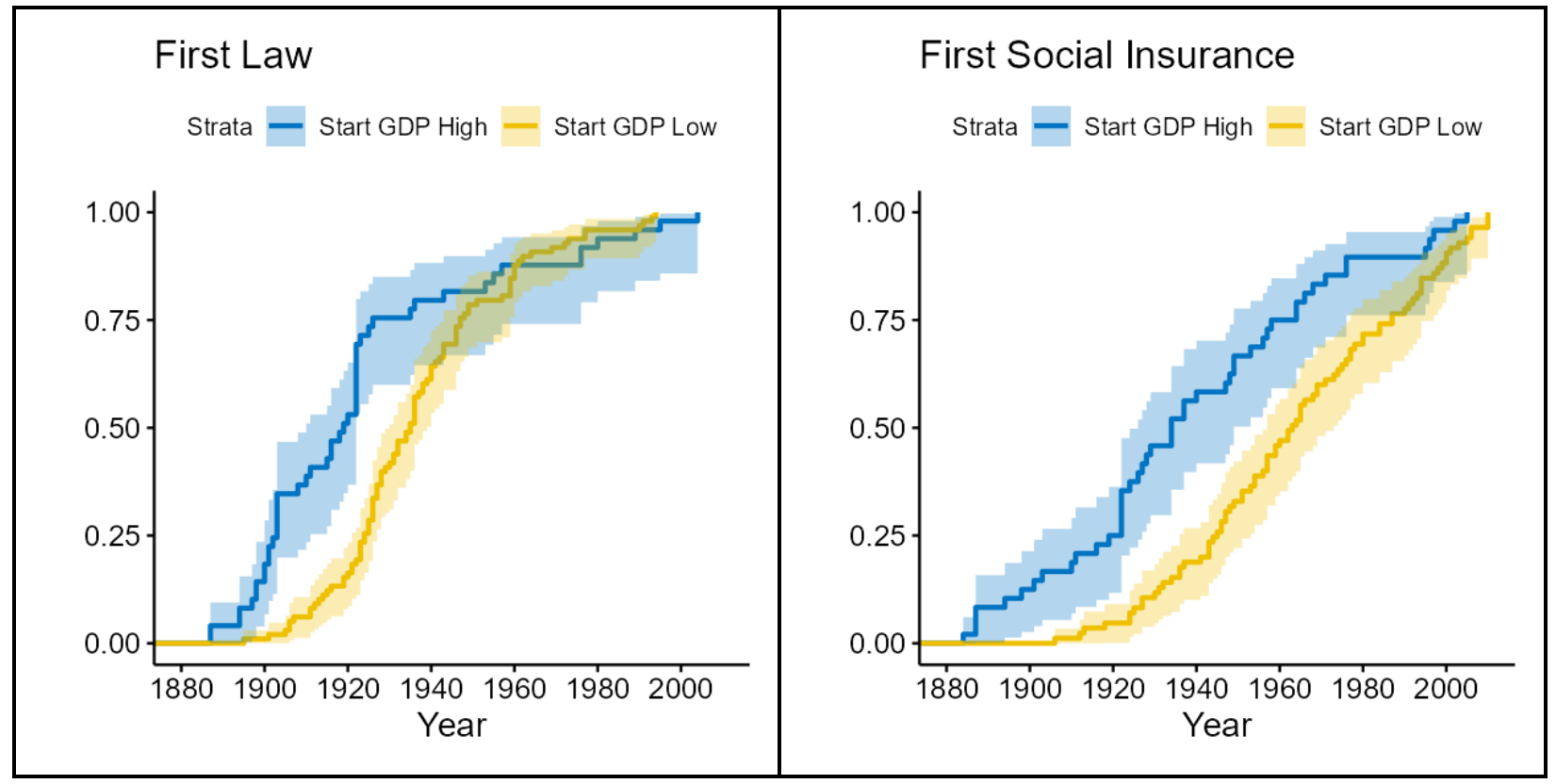

What is not so often explored in the social security and welfare state development literature is the concept of spatial proximity. The classic study by Collier and Messick (1975) and work by Castles and colleagues (Castles and Mitchell 1992) suggests that there are families of nations when it comes to social policy adoption timing. Thus, the early adopters were European, then came the British influence sphere (New World and Japan) and then Latin America and so forth. Our study reveals more about the mechanisms behind this process than the previous works because it includes multivariate event history modeling with 
network diffusion effects. This gives a direct statistical link of dyadic ties and network weighting as a model of the theoretical reality of social exchange and transmission of ideas through the convenience of spatial contact.

In a way our study opens a new area for researchers to attempt to disentangle trade - what is passed through actions related to economic exchange - from the transmission of ideas based on both convenience and political networks. We assume that ideas passing through international organizations such as the ILO, religious and charity organizations, the Communist party and university exchanges are endogenous to our measure of trade partnerships. States that trade more with each other also have exchanges in these other areas. This is often facilitated by shared culture, language or geopolitical agendas. As our reproducible code and data are freely available we look forward to researchers expanding on our ideas and models. Nonetheless, the trade effect is striking and we are not aware of a strong theory of policy diffusion based on trade in the welfare state literature.

\section{Conclusion}

Using an event history time-series model of 150 countries from 1880-2010 with the inclusion of network diffusion variables, we show that state formation is an important statistical predictor of the introduction of a first work-injury law in a given nation's history. It is an even more important predictor of a first social insurance law, increasing the likelihood of adoption during the 5-year early state formation phase by 18 fold. This points at the important role of social insurance in state building. Of course, stronger states with more wealth or geopolitical power were more likely to adopt social insurance, especially earlier in their histories, as with the colonial empires of Western Europe and later the Russian Communist Party 'empire' constructed via the Soviet Union where countries adopted social insurance as part of the system of socialism. Both western and eastern Europe saw social insurance arrive after the start of industrialization, but the former did it without workers overthrowing their governments. In both cases workers attaining social protections, in addition to expanded rights in the transition out of serfdom, represented a means of constructing a nation in addition to a state (western Europe) or a nation in opposition to the existing state (Russian and Communist revolutions). The cohesiveness of the nation, or what many refer to as solidarity, was built on this enfranchisement and protection of workers, who in exchange offered more efficient or effective labor to improve the state.

We argue that state formation and strengthening is compatible with power resource theories. Once established, the state is vying for complete control over the individuals and organizations within it. Moreover, without a productive workforce that has a sense of national unity, the state is less likely to be 
as economically competitive or as defensible against outside invasions. We expect a similar mechanism is at play between states and industrial workers as with states strategically using social provisions to improve the number of soldiers and their willingness to fight for the nation. Thus, the introduction of a social insurance scheme that covers all formal industrial workers is a monumental state achievement and institutionalizes the state in a way not present beforehand. Essentially the welfare of the state and worker become coterminous, where each has an interest in the other via social insurance.

There are limitations to this study. In particular, the timing of nation state formation is difficult to measure. Germany became an independent state in 1871 but there was a German people before that arguably constituted a nation albeit within various forms of empire. After that, the geopolitical form of Germany changed during and after the World Wars, and then again with reunification. This is nothing particularly unique to Germany. Poland has had shifting borders throughout the 19th and early 20th Centuries as has China and countries that once comprised the Soviet Union. Austria is another challenging measurement case because it was part of the Austria-Hungarian Empire, but also operated as a semi-autonomous state introducing social insurance for miners in 1854 independently of the empire. Therefore, we should proceed with caution in interpreting results as state formation is not a discrete event in many cases, but an ongoing contested process. Finally, colonialism may play a role in work-injury policy even though we found no clear association, because the effect is confounded by culture and spatial proximity, which many former colonies have in common to some extent.

We did not expect an effect of state formation on the introduction of a first work-injury law as these were largely not social insurance laws, but employer liability laws that were ineffectual at staving work-related risks. The effect of state formation on social insurance for blue-collar workers was much larger than on first work-injury laws statistically speaking, but it is not as clear cut as we expected. It is possible that employer liability had a role in appeasing workers in the very short term as a symbolic act, and was thus a step in the nation state construction process, if only a symbolic step. As we measured introduction of policies, we do not capture further developments of the state whereby policies are expanded in benefits and coverage and create even more solidarity, i.e., nation building. Given the new global data now available for investigating such phenomena, we see great potential for further investigation of this and other classic research on the welfare state that has been characterized by a focus on the Global North. 


\section{Literature}

Abbott, Andrew and Stanley DeViney. 1992. "The Welfare State as Transnational Event: Evidence from Sequences of Policy Adoption”. Social Science History 16(2): 245-274.

Alber, Jens. 1982. Vom Armenhaus zum Wohlfahrtsstaat: Analysen zur Entwicklung der Sozialversicherung in Westeuropa. Campus-Verlag.

Béland, Daniel and Michal Koreh. 2019. "Social Insurance as Fiscal Policy and State-Building Tool: The Development and Politics of Payroll Contributions in Israel and Canada". Journal of Social Policy 48(1): 1-20.

Berkowitz, Edward and Monroe Berkowitz. 1984. “The Survival of Workers' Compensation”. Social Service Review 58(2): 259-280.

Breznau, Nate. 2020. "The Introduction and Expansion of Work-Injury Law: Testing the Global Role of Worker Agency"., https:/osf.io/preprints/socarxiv/kys9w/ (last accessed January 12, 2021).

Breznau, Nate and Felix Lanver. 2020. Global Work-Injury Policy Database (GWIP): Project Overview and Codebook. 4, Bremen, Germany: Collaborative Research Center SFB 1342 'The Global Dynamics of Social Policy', https://www.socialpolicydynamics.de/f/eb5f6f0e54.pdf.

Castles, Francis and Deborah Mitchell. 1992. "Identifying Welfare State Regimes: The Links Between Politics, Instruments and Outcomes". Governance 5(1): 1-26.

Collier, David and Richard E. Messick. 1975. "Prerequisites Versus Diffusion: Testing Alternative Explanations of Social Security Adoption”. American Political Science Review 69(4): 12991315.

Egger, Peter, Doina Radulescu and Nora Strecker. 2017. "On the Spread of Social Protection Systems". International Tax and Public Finance 24(4): 550-574.

Flora, Peter and Jens Alber. 2009. "Modernization, Democratization, and the Development of Welfare States in Western Europe" In The Development of Welfare states in Europe and America [originally published 1976], New Brunswick and London: Transaction Publishers, 37-80.

Gordon, Andrew. 1985. 117 The Evolution of Labor Relations in Japan: Heavy Industry, 1853-1955. 1st ed. Harvard University Asia Center.

Grünewald, Aline. 2021. 'From Benefits and Beneficiaries. The Historical Origins of Old-Age Pensions from a Political Regime Perspective.' Comparative Political Studies (Forthcoming).

Haggard, Stephan and Robert R Kaufman. 2008. Development, democracy, and welfare states: Latin America, East Asia, and eastern Europe. Princeton University Press.

Ierley, Merritt. 1984. With charity for all: welfare and society, ancient times to the present. Praeger Publishers.

Kangas, Olli. 2010. "Work Accident and Sickness Benefits". The Oxford Handbook of the Welfare State, https://www.oxfordhandbooks.com/view/10.1093/oxfordhb/9780199579396.001.0001/oxfordhb9780199579396-e-27 (last accessed October 2, 2020).

Korpi, Walter. 1983. The democratic class struggle. London; Boston: Routledge \& K. Paul.

Liu, Tao and Lutz Leisering. 2017. "Protecting injured workers: how global ideas of industrial accident insurance travelled to China". Journal of Chinese Governance 2(1): 106-123.

Marshall, T H. 1950. Citizenship and Social Class and Other Essays. Cambridge: Cambridge University Press.

Obinger, Herbert, Klaus Petersen and Peter Starke, eds. 2018. "Introduction: Studying the Welfare-War Nexus" In Warfare and welfare: military conflict and welfare state development in Western countries, Oxford: Oxford University Press, .

Pavalko, Eliza K. 1989. "State Timing of Policy Adoption: Workmen's Compensation in the United States, 1909-1929”. American Journal of Sociology 95(3): 592-615.

Schmitt, Carina. 2015. "Social Security Development and the Colonial Legacy". World Development 70: 332-342.

Tripp, Joseph F. 1976. “An instance of labor and business cooperation: Workmen's compensation in 
Washington state (1911)". Labor History 17(4): 530-550.

Wilensky, Harold L. 1975. The Welfare State and Equality: Structural and Ideological Roots of Public

Expenditures. Rebound in Cardboard/EX-LIBRARY. Berkeley, Calif.: UNIV OF CALIFORNIA PR. 


\section{Appendix Table 1}

\begin{tabular}{|c|c|c|c|c|c|c|}
\hline \multirow[b]{2}{*}{ Time-period Intercepts } & \multicolumn{3}{|c|}{ DV: First Law } & \multicolumn{3}{|c|}{ DV: First Social Insurance } \\
\hline & $\begin{array}{l}\text { Model } \\
1 \mathrm{~A}\end{array}$ & $\begin{array}{l}\text { Model } \\
2 \mathrm{~A}\end{array}$ & $\begin{array}{l}\text { Model } \\
3 \mathrm{~A}\end{array}$ & $\begin{array}{l}\text { Model } \\
\text { 1B }\end{array}$ & $\begin{array}{l}\text { Model } \\
\text { 2B }\end{array}$ & $\begin{array}{l}\text { Model } \\
\text { 3B }\end{array}$ \\
\hline$(1880-1902)$ & $0.004 *$ & $0.004 *$ & $0.004 *$ & $0.002 *$ & $0.002 *$ & $0.002 *$ \\
\hline (1903-1928) & $0.006^{*}$ & $0.006^{*}$ & $0.006^{*}$ & $0.004 *$ & $0.004^{*}$ & $0.003^{*}$ \\
\hline$(1929-1954)$ & $0.002 *$ & $0.002 *$ & $0.002 *$ & $0.004 *$ & $0.004 *$ & $0.004 *$ \\
\hline$(1955-1979)$ & $0.001 *$ & $0.002 *$ & $0.001 *$ & $0.004 *$ & $0.003^{*}$ & $0.003^{*}$ \\
\hline$(1980-2010)$ & $0.001 *$ & $0.002 *$ & $0.001^{*}$ & $0.003 *$ & $0.003^{*}$ & $0.002 *$ \\
\hline \multicolumn{7}{|l|}{ Independent Variables } \\
\hline State Founded (last 4 years) & & 1.325 & 1.401 & & $2.435^{*}$ & $2.697 *$ \\
\hline Network Exposure: Culture (t-1) & $71.811^{*}$ & $72.377 *$ & 11.584 & 14.136 & 24.441 & 2.692 \\
\hline Network Exposure: Colonial & 1.229 & 1.121 & 0.349 & 0.152 & 0.085 & $0.039+$ \\
\hline Network Exposure: Trade (t-1) & 1.026 & 1.007 & 0.839 & $7.648^{*}$ & $7.085^{*}$ & $5.304^{*}$ \\
\hline $\begin{array}{l}\text { Network Exposure: Spatial } \\
\text { Proximity }\end{array}$ & & & $30.936^{*}$ & & & $37.793 *$ \\
\hline GDP per capita & 0.985 & 0.982 & 1.002 & 0.906 & 0.915 & 0.895 \\
\hline Democratization & $1.290^{*}$ & $1.283^{*}$ & $1.260^{*}$ & $1.160^{*}$ & $1.140^{*}$ & $1.144^{*}$ \\
\hline \multicolumn{7}{|l|}{ Model Statistics } \\
\hline Countries & 164 & 164 & 164 & 164 & 164 & 164 \\
\hline Observations & 7,870 & 7,870 & 7,870 & 12,269 & 12,269 & 12,269 \\
\hline Log Likelihood & -657.15 & -656.87 & -651.422 & -651.747 & -647.375 & -642.314 \\
\hline AIC & 1334.299 & 1335.739 & 1326.843 & 1323.494 & 1316.751 & 1308.628 \\
\hline
\end{tabular}

Note: * coefficieint is statistically different from zero at 99\%CI using robust Huber-White standard errors by country. Coefficients are odds-ratios indicating the increase in likelihood of adopting the dependent variable in a given year conditional on the other covariates. 